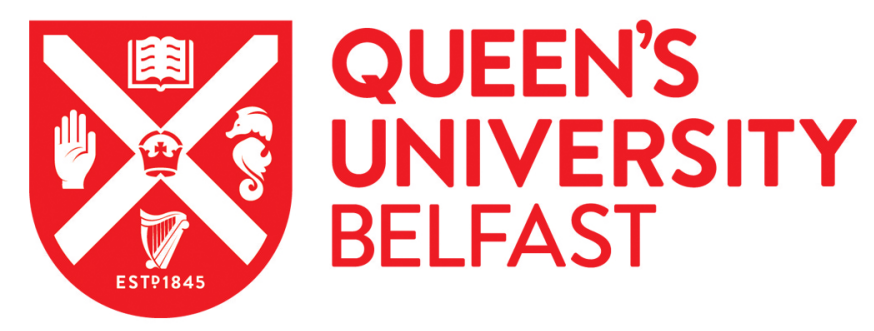

\title{
Who will be wielding the lancet for China's patients in the future?
}

Jiang, Y., Luo, L., Congdon, N., Wang, S., \& Liu, Y. (2016). Who will be wielding the lancet for China's patients in the future? Lancet, 388(10054), 1952-1954. https://doi.org/10.1016/S0140-6736(16)31792-5

\section{Published in:}

Lancet

\section{Document Version:}

Peer reviewed version

Queen's University Belfast - Research Portal:

Link to publication record in Queen's University Belfast Research Portal

\section{Publisher rights}

(c) Elsevier Ltd 2016. This manuscript version is made available under the CC-BY-NC-ND 4.0 license http://creativecommons.org/licenses/by$\mathrm{nc}-\mathrm{nd} / 4.0 /$ which permits distribution and reproduction for non-commercial purposes, provided the author and source are cited.

\section{General rights}

Copyright for the publications made accessible via the Queen's University Belfast Research Portal is retained by the author(s) and / or other copyright owners and it is a condition of accessing these publications that users recognise and abide by the legal requirements associated with these rights.

Take down policy

The Research Portal is Queen's institutional repository that provides access to Queen's research output. Every effort has been made to ensure that content in the Research Portal does not infringe any person's rights, or applicable UK laws. If you discover content in the Research Portal that you believe breaches copyright or violates any law, please contact openaccess@qub.ac.uk. 
Elsevier Editorial System(tm) for The Lancet Manuscript Draft

Manuscript Number: THELANCET-D-16-04814R1

Title: Who will be wielding the lancet for china's patients in the future?

Article Type: Viewpoint

Corresponding Author: Prof. Yizhi Liu, Ph.D., M.D.

Corresponding Author's Institution: Zhongshan Ophthalmic Center, Sun Yatsen University

First Author: Yuzhen Jiang, MD PhD

Order of Authors: Yuzhen Jiang, MD PhD; Lixia Luo, MD PhD; Nathan

Congdon, MD PhD; Shenming Wang, MD PhD; Yizhi Liu, Ph.D., M.D. 
a. State Key Laboratory of Ophthalmology, Zhongshan Ophthalmic Center, Sun Yatsen University, Guangzhou, China;

b. UCL Institute of Ophthalmology, University College London and Moorfields Eye Hospital, London, UK;

c. Orbis International, New York, USA;

d. Queen's University Belfast, Belfast, UK;

e. Department of Vascular Surgery, First Affiliated Hospital, Sun Yat-sen University, Guangzhou, China

14 *The first authorship is shared by Yuzhen Jiang and Lixia Luo. 
Access to high-quality surgical treatment is an indispensable part of a well-functioning healthcare system, and as the Amsterdam Declaration on Essential Surgical Care ${ }^{1}$ has recently emphasized, there are important shortfalls in surgical service in many parts of the world. Recognising this, the Chinese government has made notable recent efforts to standardise surgical training programs, as part of the National Health and Family Planning Commission's (NHFPC) complete set of model residency training programs. ${ }^{2}$ Though the effort is laudable, the lack of credible mandatory minimums for procedures performed, and of clear quality assurance systems, has left a major training gap unaddressed.

The biggest challenge facing surgical trainees at all levels in mainland China today is the lack of hands-on learning opportunities. Taking cataract surgery as an example, a recent study including China's best known eye hospitals found mainland Chinese residents had performed a median of zero independent cataract operations during their training, as compared to 100 cases for trainees in the Hong Kong Special Administrative Region (HKSAR) over a similar period ${ }^{3}$. Differences in national requirements clearly tell a part of the story: the current minimum standard for cataract surgeries is 100 cases by the completion of residency training in HKSAR ${ }^{4}$, 86 in both the United Sates ${ }^{5}$ and Singapore ${ }^{6}$ and 350 in the United Kingdom ${ }^{7}$, whereas the required number of cases for residents in training in China is only 15 according to regulations recently published by the Chinese National Health and Family Planning Commission. ${ }^{8}$ It has been shown that some $90 \%$ of US residents exceed the national target ${ }^{9}$, which does not appear to be the case in China ${ }^{3}$. Differing approaches to enforcement of existing standards also appear to play a role: in the $\mathrm{US}^{10}, \mathrm{HKSAR}^{11}$ and other countries, programs not providing adequate training for residents risk losing accreditation, but the same consequences do not generally exist in China.

Unfortunately, this problem of lack of access to hands-on surgical opportunities is not limited to ophthalmology, nor does it end with the completion of formal residency training. ${ }^{12,13}$ Recent studies have shown that the majority of general surgeries in large Chinese tertiary hospitals were performed by a small pool of senior doctors, with young surgeons having very limited chances to operate, performing only $7 \%$ of surgeries in one report. ${ }^{12}$ Our own data from departments of ophthalmology, gynaecology, obstetrics and general surgery in two tertiary hospitals in southern China show that only 0.3 to $4.8 \%$ of surgeries were completed by surgeons aged 24 to 43 , and 63.3 to $79.1 \%$ by those over 50 , usually a small handful of practitioners in each department.

What are the consequences of this top-heavy approach to surgical service delivery? Inevitably, when too few surgeons are permitted to practice, a service bottleneck is created, and output suffers. Once again taking cataract as a convenient example, for which national statistics are widely available, the cataract surgical rate in China is currently some 1100 cases/million/year. This has grown rapidly in recent years thanks to coordinated national efforts on the part of the NHFPC, but still remains lower than that for China's less well-off neighbors. There can also be a worrisome impact on the morale of young trainees: a recent survey ${ }^{3}$ found that $69.4 \%$ of young Chinese surgical trainees did not want their children to practice medicine, a gloomy prognosis borne out by other reports from the pages of this journal. ${ }^{14}$ This bodes poorly for attracting the best and the brightest to a surgical career in China.

57 There are also obvious consequences from the standpoint of workforce supply. As noted above, 58 many of the most active clinicians currently practicing in large Chinese hospitals are above 50. 
The age of mandatory retirement for those in government posts, who constitute the majority of busy surgeons, is 60 . Given that it takes at least 5 years to finish basic skill training, followed by 3 to 5 years of intensive hands-on practice under supervision, there are real concerns about the ability of China's pipeline to replace the current generation of senior surgeons over the next decade.

A variety of factors contribute to the concentration of surgical caseloads among senior practitioners. Numerous hospitals in China still utilise surgical output as the principal Key Performance Indicator (KPI) in determining surgeons' incomes. Teaching performance is by contrast under-emphasised, creating a clear incentive for senior surgeons to operate rather than teach. This results in less supervision and a greater burden of paperwork for trainees and junior surgeons, allowing senior surgeons to concentrate on cases. Only $4 \%$ of ophthalmology residents in mainland China reported that $>=90 \%$ of their training occurred with adequate supervision, compared to $65 \%$ of those in HKSAR, and two thirds of Chinese residents spent more than half of their time completing charts, compared to $5 \%$ in $\mathrm{HKSAR}^{3}$. Excessive pressure to engage in research ${ }^{3,15}$ has also been identified as a competing priority which diverts surgical trainees from engaging in more hands-on learning.

Financial pressures on Chinese public hospitals also play a role: government investment supports only $8 \%$ of their budgets, ${ }^{16}$ leading to a reliance on high-volume service provision to generate income. ${ }^{16,17}$ Many hospitals choose to market "celebrity doctors" as a means of increasing volume, which also further directs patient flow toward senior surgeons. Patients have little financial disincentive to seek out well-known names: China's medical insurance system allows patients to freely select their surgeon, and very little difference exists in the fees for those at different levels of seniority. ${ }^{12-14}$ Poor doctor-patient relationships in China and the consequent lack of trust further exacerbates patients' unwillingness to rely on young surgeons' expertise, and the strong preference for highly experienced practitioners. ${ }^{18}$ Senior surgeons, for their part, are often unwilling to take responsibility for any complications resulting from younger surgeons' involvement.

How to fix the problem? In the first place, the Chinese government clearly must mandate reasonable training models and minimum numbers of cases that reflect international standards. Assessment systems are needed which emphasise teaching and not only surgical output. ${ }^{19}$ And as in other countries, accreditation of teaching hospitals should be based on assessment against national criteria and annual audits on performance. National standards should also be established for training and certification of trainers. As the largest national association of medical professionals in China, the Chinese Medical Association (CMA) is well positioned to help the government gather front-line data and make informed decisions. Adequate governmental financial support for resident training programs is also needed. The twin burdens of paperwork and research on young trainees must also be rationalised. Doctors and hospitals need to be transparent with patients about their teaching responsibilities, with clear protections in place for patients, including adequate supervision of trainees. Further research is needed documenting how these approaches can best be implemented, and tracking their impact on the problem. 
Other issues are more challenging to manage, none more so than China's culture, among the world's oldest and greatest. China's Confucian veneration of learning has done much to propel the country to its current place as a world leader, but it is fair to say that deep Chinese respect for teachers might be an even more potent force if matched with commensurate regard for students. Further, compared to the situation in America and Europe, a profound lack of trust exists between doctors and patients in China, which contributes for example to well-publicised cases of assault against physicians. ${ }^{20}$ This is to some extent a product of the rapid commercialization of medicine in China, as with so many other facets of society. For patients to place their sight or health in the hands of a younger, less-experienced surgeon is ultimately an act of faith, predicated on mutual respect and concern for well-being. China desperately needs to train a new generation of hands to take up the scalpel now and in the future. Bureaucratic reforms are urgently needed as part of the solution, but will go only so far to address the problem. China's senior physicians themselves need to find a way to bring young colleagues forward more efficiently, and to heal the badly-wounded bond between doctor and patient.

\section{References}

1. Botman M, Meester RJ, Voorhoeve R, et al. The Amsterdam Declaration on Essential Surgical Care. World J Surg 2015; 39(6): 1335-40.

2. Wang C QX, Chen X, Yu Q, Xing L. [The establishment of China standardized residency training system]. National Medical Journal of China 2015; 95(14): 1041-3.

3. Young $A L$, Jhanji $V$, Liang $Y$, et al. A survey of perceived training differences between ophthalmology residents in Hong Kong and China. BMC Med Educ 2015; 15: 158.

4. Training Curriculum. Hong Kong: The College of Ophthalmologists of Hong Kong; 2000. Available from: www.hkam.org.hk/fellowship/traindocs/op/TrainingCurriculum.doc. Last accessed: December 17, 2013.

5. Accreditation Council for Graduate Medical Education. Required Minimum Number of Procedures for Graduating Residents in Ophthalmology. Review Committee for Ophthalmology. http://www.acgme.org/acgmeweb/Portals/0/PFAssets/ProgramResources/240 Oph Minimum Numbers.pdf. Last accessed October 3, 2013.

6. Singapore Country Addendum to the ACGME-I Advanced Specialty Requirements. http://www.healthprofessionals.gov.sg/content/hprof/sab/en/topnav/specialist training/reside ncy/country addendum.html. Last accessed November 16, 2013.

7. Chan $\mathrm{WH}$, Saedon H, Falcon MG. Postgraduate ophthalmic training: how do we compare? Eye (Lond) 2011; 25(8): 965-7.

8. Contents and standards of the standardised resident training programs. http://www.nhfpc.gov.cn/aiivs/s3593/201408/946b17f463fa4e5dbcfb4f7c68834c41.shtml Last accessed: September 3, 2016

9. Yeu E, Reeves SW, Wang L, Randleman JB, Physicians AY, Residents Clinical C. Resident surgical experience with lens and corneal refractive surgery: survey of the ASCRS Young Physicians and Residents Membership. J Cataract Refract Surg 2013; 39(2): 279-84.

10. ACGME Institutional Requirements. http://www.acgme.org/acgmeweb/Portals/0/InstitutionalRequirements 07012014.pdf. Last accessed October 3, 2013. 
11. Lam PTH. The challenges of ophthalmic training and accreditation in Hong Kong. Hong

147 Kong J Ophthalmol 2007;11(1):3-6.

148 12. Zhao J, Xu C, Liu Y, Wang J. The Current Investigation of Operation Grading

149 Management in Three Affiliated Hospitals of One University. Chinese Medical Record.

$150 \quad 2015 ; 16(2): 18-20$.

151 13. Zheng J, Zhang B, Yin Y, et al. Comparison of Plastic Surgery Residency Training in United 152 States and China. Ann Plast Surg 2015; 75(6): 672-8.

153 14. Wu LX, Qi L, Li Y. Challenges faced by young Chinese doctors. Lancet 2016; 387(10028):

1541617.

155 15. Yuan HF, Xu WD, Hu HY. Young Chinese doctors and the pressure of publication. Lancet 156 2013; 381(9864): e4.

157 16. Guan X, Qi L, Liu L. Controversy in public hospital reforms in China. Lancet Glob Health 158 2016; 4(4): e240.

159 17. Yip WC, Hsiao W, Meng Q, Chen W, Sun X. Realignment of incentives for health-care 160 providers in China. Lancet 2010; 375(9720): 1120-30.

161 18. Ko F, Frick KD, Tzu J, He M, Congdon N. Willingness to pay for potential enhancements 162 to a low-cost cataract surgical package in rural southern China. Acta Ophthalmol 2012; 90(1):

163 e54-60.

164 19. Ye B, Liu AH. Inadequate evaluation of medical doctors in China. Lancet 2013; 381(9882): 1651984.

$16620 . \quad$ Ending violence against doctors in China. Lancet 2012; 379(9828): 1764.

None of the authors has conflicts of interest to disclose.

\section{Statement of Contribution}

171 Contributions of all authors are listed below

172

173 Yizhi Liu: Study design, writing and revision.

174 Yuzhen Jiang: Literature search, data interpretation, writing and revision.

175 Lixia Luo: Literature search, data collection, data interpretation, writing.

176 Nathan Congdon: Identify additional references, made substantial revisions to manuscript.

177 Shenming Wang: Provided some data, made revision to the manuscript. 
a. State Key Laboratory of Ophthalmology, Zhongshan Ophthalmic Center, Sun Yatsen University, Guangzhou, China;

b. UCL Institute of Ophthalmology, University College London and Moorfields Eye Hospital, London, UK;

c. Orbis International, New York, USA;

d. Queen's University Belfast, Belfast, UK;

e. Department of Vascular Surgery, First Affiliated Hospital, Sun Yat-sen University, Guangzhou, China

$14 \quad *$ The first authorship is shared by Yuzhen Jiang and Lixia Luo. 
Access to high-quality surgical treatment is an indispensable part of a well-functioning healthcare system, and as the Amsterdam Declaration on Essential Surgical Care ${ }^{1}$ has recently emphasized, there are important shortfalls in surgical service in many parts of the world. Recognising this, the Chinese government has made notable recent efforts to standardise surgical training programs, as part of the National Health and Family Planning Commission's (NHFPC) complete set of model residency training programs. ${ }^{2}$ Though the effort is laudable, the lack of credible mandatory minimums for procedures performed, and of clear quality assurance systems, has left a major training gap unaddressed.

The biggest challenge facing surgical trainees at all levels in mainland China today is the lack of hands-on learning opportunities. Taking cataract surgery as an example, a recent study including China's best known eye hospitals found mainland Chinese residents had performed a median of zero independent cataract operations during their training, as compared to 100 cases for trainees in the Hong Kong Special Administrative Region (HKSAR) over a similar period ${ }^{3}$. Differences in national requirements clearly tell a part of the story: the current minimum standard for cataract surgeries is 100 cases by the completion of residency training in HKSAR ${ }^{4}$, 86 in both the United Sates ${ }^{5}$ and Singapore ${ }^{6}$ and 350 in the United Kingdom ${ }^{7}$, whereas the required number of cases for residents in training in China is only 15 according to regulations recently published by the Chinese National Health and Family Planning Commission. ${ }^{8}$ It has been shown that some $90 \%$ of US residents exceed the national target ${ }^{9}$, which does not appear to be the case in China ${ }^{3}$. Differing approaches to enforcement of existing standards also appear to play a role: in the $\mathrm{US}^{10}, \mathrm{HKSAR}^{11}$ and other countries, programs not providing adequate training for residents risk losing accreditation, but the same consequences do not generally exist in China.

Unfortunately, this problem of lack of access to hands-on surgical opportunities is not limited to ophthalmology, nor does it end with the completion of formal residency training. ${ }^{12,13}$ Recent studies have shown that the majority of general surgeries in large Chinese tertiary hospitals were performed by a small pool of senior doctors, with young surgeons having very limited chances to operate, performing only $7 \%$ of surgeries in one report. ${ }^{12}$ Our own data from departments of ophthalmology, gynaecology, obstetrics and general surgery in two tertiary hospitals in southern China show that only 0.3 to $4.8 \%$ of surgeries were completed by surgeons aged 24 to 43 , and 63.3 to $79.1 \%$ by those over 50 , usually a small handful of practitioners in each department.

What are the consequences of this top-heavy approach to surgical service delivery? Inevitably, when too few surgeons are permitted to practice, a service bottleneck is created, and output suffers. Once again taking cataract as a convenient example, for which national statistics are widely available, the cataract surgical rate in China is currently some 1100 cases/million/year. This has grown rapidly in recent years thanks to coordinated national efforts on the part of the NHFPC, but still remains lower than that for China's less well-off neighbors. There can also be a worrisome impact on the morale of young trainees: a recent survey ${ }^{3}$ found that $69.4 \%$ of young Chinese surgical trainees did not want their children to practice medicine, a gloomy prognosis borne out by other reports from the pages of this journal. ${ }^{14}$ This bodes poorly for attracting the best and the brightest to a surgical career in China.

57 There are also obvious consequences from the standpoint of workforce supply. As noted above, 58 many of the most active clinicians currently practicing in large Chinese hospitals are above 50. 
The age of mandatory retirement for those in government posts, who constitute the majority of busy surgeons, is 60 . Given that it takes at least 5 years to finish basic skill training, followed by 3 to 5 years of intensive hands-on practice under supervision, there are real concerns about the ability of China's pipeline to replace the current generation of senior surgeons over the next decade.

A variety of factors contribute to the concentration of surgical caseloads among senior practitioners. Numerous hospitals in China still utilise surgical output as the principal Key Performance Indicator (KPI) in determining surgeons' incomes. Teaching performance is by contrast under-emphasised, creating a clear incentive for senior surgeons to operate rather than teach. This results in less supervision and a greater burden of paperwork for trainees and junior surgeons, allowing senior surgeons to concentrate on cases. Only $4 \%$ of ophthalmology residents in mainland China reported that $>=90 \%$ of their training occurred with adequate supervision, compared to $65 \%$ of those in HKSAR, and two thirds of Chinese residents spent more than half of their time completing charts, compared to $5 \%$ in $\mathrm{HKSAR}^{3}$. Excessive pressure to engage in research ${ }^{3,15}$ has also been identified as a competing priority which diverts surgical trainees from engaging in more hands-on learning.

Financial pressures on Chinese public hospitals also play a role: government investment supports only $8 \%$ of their budgets, ${ }^{16}$ leading to a reliance on high-volume service provision to generate income. ${ }^{16,17}$ Many hospitals choose to market "celebrity doctors" as a means of increasing volume, which also further directs patient flow toward senior surgeons. Patients have little financial disincentive to seek out well-known names: China's medical insurance system allows patients to freely select their surgeon, and very little difference exists in the fees for those at different levels of seniority. ${ }^{12-14}$ Poor doctor-patient relationships in China and the consequent lack of trust further exacerbates patients' unwillingness to rely on young surgeons' expertise, and the strong preference for highly experienced practitioners. ${ }^{18}$ Senior surgeons, for their part, are often unwilling to take responsibility for any complications resulting from younger surgeons' involvement.

How to fix the problem? In the first place, the Chinese government clearly must mandate reasonable training models and minimum numbers of cases that reflect international standards. Assessment systems are needed which emphasise teaching and not only surgical output. ${ }^{19}$ And as in other countries, accreditation of teaching hospitals should be based on assessment against national criteria and annual audits on performance. National standards should also be established for training and certification of trainers. As the largest national association of medical professionals in China, the Chinese Medical Association (CMA) is well positioned to help the government gather front-line data and make informed decisions. Adequate governmental financial support for resident training programs is also needed. The twin burdens of paperwork and research on young trainees must also be rationalised. Doctors and hospitals need to be transparent with patients about their teaching responsibilities, with clear protections in place for patients, including adequate supervision of trainees. Further research is needed documenting how these approaches can best be implemented, and tracking their impact on the problem. 
Other issues are more challenging to manage, none more so than China's culture, among the world's oldest and greatest. China's Confucian veneration of learning has done much to propel the country to its current place as a world leader, but it is fair to say that deep Chinese respect for teachers might be an even more potent force if matched with commensurate regard for students. Further, compared to the situation in America and Europe, a profound lack of trust exists between doctors and patients in China, which contributes for example to well-publicised cases of assault against physicians. ${ }^{20}$ This is to some extent a product of the rapid commercialization of medicine in China, as with so many other facets of society. For patients to place their sight or health in the hands of a younger, less-experienced surgeon is ultimately an act of faith, predicated on mutual respect and concern for well-being. China desperately needs to train a new generation of hands to take up the scalpel now and in the future. Bureaucratic reforms are urgently needed as part of the solution, but will go only so far to address the problem. China's senior physicians themselves need to find a way to bring young colleagues forward more efficiently, and to heal the badly-wounded bond between doctor and patient.

\section{References}

1. Botman M, Meester RJ, Voorhoeve R, et al. The Amsterdam Declaration on Essential Surgical Care. World J Surg 2015; 39(6): 1335-40.

2. Wang C QX, Chen X, Yu Q, Xing L. [The establishment of China standardized residency training system]. National Medical Journal of China 2015; 95(14): 1041-3.

3. Young $A L$, Jhanji $V$, Liang $Y$, et al. A survey of perceived training differences between ophthalmology residents in Hong Kong and China. BMC Med Educ 2015; 15: 158.

4. Training Curriculum. Hong Kong: The College of Ophthalmologists of Hong Kong; 2000. Available from: www.hkam.org.hk/fellowship/traindocs/op/TrainingCurriculum.doc. Last accessed: December 17, 2013.

5. Accreditation Council for Graduate Medical Education. Required Minimum Number of Procedures for Graduating Residents in Ophthalmology. Review Committee for Ophthalmology. http://www.acgme.org/acgmeweb/Portals/0/PFAssets/ProgramResources/240 Oph Minimum Numbers.pdf. Last accessed October 3, 2013.

6. Singapore Country Addendum to the ACGME-I Advanced Specialty Requirements. http://www.healthprofessionals.gov.sg/content/hprof/sab/en/topnav/specialist training/reside ncy/country addendum.html. Last accessed November 16, 2013.

7. Chan WH, Saedon H, Falcon MG. Postgraduate ophthalmic training: how do we compare? Eye (Lond) 2011; 25(8): 965-7.

8. Contents and standards of the standardised resident training programs. http://www.nhfpc.gov.cn/aiivs/s3593/201408/946b17f463fa4e5dbcfb4f7c68834c41.shtml Last accessed: September 3, 2016

9. Yeu E, Reeves SW, Wang L, Randleman JB, Physicians AY, Residents Clinical C. Resident surgical experience with lens and corneal refractive surgery: survey of the ASCRS Young Physicians and Residents Membership. J Cataract Refract Surg 2013; 39(2): 279-84. 10. ACGME Institutional Requirements. http://www.acgme.org/acgmeweb/Portals/0/InstitutionalRequirements 07012014.pdf. Last accessed October 3, 2013. 
11. Lam PTH. The challenges of ophthalmic training and accreditation in Hong Kong. Hong

147 Kong J Ophthalmol 2007;11(1):3-6.

148 12. Zhao J, Xu C, Liu Y, Wang J. The Current Investigation of Operation Grading

149 Management in Three Affiliated Hospitals of One University. Chinese Medical Record.

$150 \quad 2015 ; 16(2): 18-20$.

151 13. Zheng J, Zhang B, Yin Y, et al. Comparison of Plastic Surgery Residency Training in United 152 States and China. Ann Plast Surg 2015; 75(6): 672-8.

153 14. Wu LX, Qi L, Li Y. Challenges faced by young Chinese doctors. Lancet 2016; 387(10028):

1541617.

155 15. Yuan HF, Xu WD, Hu HY. Young Chinese doctors and the pressure of publication. Lancet 156 2013; 381(9864): e4.

157 16. Guan X, Qi L, Liu L. Controversy in public hospital reforms in China. Lancet Glob Health 158 2016; 4(4): e240.

159 17. Yip WC, Hsiao W, Meng Q, Chen W, Sun X. Realignment of incentives for health-care 160 providers in China. Lancet 2010; 375(9720): 1120-30.

161 18. Ko F, Frick KD, Tzu J, He M, Congdon N. Willingness to pay for potential enhancements 162 to a low-cost cataract surgical package in rural southern China. Acta Ophthalmol 2012; 90(1):

163 e54-60.

164 19. Ye B, Liu AH. Inadequate evaluation of medical doctors in China. Lancet 2013; 381(9882): 1651984.

$16620 . \quad$ Ending violence against doctors in China. Lancet 2012; 379(9828): 1764.

None of the authors has conflicts of interest to disclose.

\section{Statement of Contribution}

171 Contributions of all authors are listed below

172

173 Yizhi Liu: Study design, writing and revision.

174 Yuzhen Jiang: Literature search, data interpretation, writing and revision.

175 Lixia Luo: Literature search, data collection, data interpretation, writing.

176 Nathan Congdon: Identify additional references, made substantial revisions to manuscript.

177 Shenming Wang: Provided some data, made revision to the manuscript. 
Dear Editors and Reviewers,

We are very grateful for the comments and suggestions made during review of our manuscript. We have responded to the editors' and each of the reviewers' comments point by point here. We do hope that we have addressed each of them adequately:

Editorial points which must be addressed:

1. Please indicate after each of the reviewers' points the text changes which have been ma de (if any) and the line number on the revised manuscript at which your change can be fou nd. [Line numbers can be added to your word document using the 'page layout' tab. Pleas e select continuous numbers.]

\section{RESPONSE:}

Continuous line numbers have been added to this revised manuscript. Line numbers will be indicated in replies to reviewers' points.

2. When interpreting editorial points made by reviewers, please remember we will further e dit the final manuscript if accepted

\section{RESPONSE:}

We are fully aware of and amenable to this. Many thanks.

3. Please indicate any authors who are full professors

\section{RESPONSE:}

The following 3 authors are full professors:

Professor Yizhi Liu

Professor Nathan Congdon

Professor Shenming Wang

This has been indicated in the author list.

Another author, Lixia Luo, is Associate Professor, please instruct if this needs to be indicated similarly in the manuscript as well.

\section{Please provide the text, tables and figures in an editable format.}

\section{RESPONSE:}

Yes. All texts of this manuscript are prepared in editable format.

5. If you have not yet done so, please return all signed authorship statements and conflict of interest forms. We also require signed statements from any named person in the ackno wledgements saying that they agree to be acknowledged

RESPONSE: 
Signed authorship statements and conflict of interest forms of all authors have been prepared and are now returned with this revised manuscript.

6. Please ensure there is a statement of contributions explaining what each author contrib uted at the end of the text

RESPONSE:

A statement of contributions has been added to the end of the text following references.

7. As corresponding author, please confirm that all authors have seen and approved of the final text

\section{RESPONSE:}

I hereby would like to confirm that all authors have seen and approved of the final text

8. Our production system is not compatible with Endnotes. Please convert to normal text.

RESPONSE:

All Endnote references have been converted to normal text.

9. Please be aware that the maximum number of references for a viewpoint article is $20 \mathrm{r}$ eferences. Please do not exceed this limit.

RESPONSE:

We have reduced the number of references to 20 as requested.

10. I am aware that the reviewers have requested additional material; however, please d o not exceed the 1500 words limit when revising your article.

\section{RESPONSE:}

Many thanks for the kind reminder. The current word count is below 1500 .

\section{COMMENTS TO THE AUTHOR:}

\section{Reviewer \#2:}

The authors in current manuscript "Who will be wielding the lancet for China's patients in $t$ he future? " reported several shortfalls in the surgical training programs in China. The aut hors pointed out the challenges including the lack of hands-

on learning opportunities and a clearly defined quality assurance system.

The authors suggested that the Chinese government mandate reasonable training models and minimum numbers of cases and reconstruct the trust between doctors and patients in China. However these problems are not easy to fix in China in a short term. Overall, the vi ewpoint is important and it should be addressed urgently.

This Viewpoint investigated the status of China's current physician training system, surge ons' incomes, and health insurance system. Starting from young doctors hands-

on surgical training, the authors try to reach the reason of doctor- 
patient relationship strained in China. The authors also made some possible solutions. $\mathrm{Bu}$ $t$ taking into account China's large population and violence against doctors situation now, this problem is not easily solved in a short time. In this paper, the authors disclosure thes e important issues, hoping to attract more attention, and prompt managements think abou t how to address.

1. The data about ratio of surgeries performing by young surgeons is from few references and a $f$ ew hospitals. Is this a common phenomenon? Can authors include more data?

\section{RESPONSE:}

The reviewer is correct to imply that China is a large country, and it would require a full-length scholarly book to document exhaustively surgical practices in all specialties throughout the nation. We have, however, include our own data on several sub-specialties, and that of other publications covering a number of different institutions. The authors do feel that strongly similar trends in the deficit of opportunities for young surgeons and the large majority of cases performed by senior doctors is really quite striking across specialties and institutions. This is also why further studies are needed based on wide attention to this topic. Line 99-101 now read:

"Further research is needed documenting how these approaches can best be implemented, and tracking their impact on the problem."

Reviewer \#3: Generally, this is a nice piece of Viewpoint, which sheds some light on the qu ality improvement of China's residency education in surgery and ophthalmology. The surg ical trainees desperately need much more hands-

on practice opportunities. This manuscript covers many aspects of the problem, the factor $s$ contributing to the problem as well as some potential solutions. The manuscript has rais ed a key issue of great importance, but still it needs some improvements.

There are three MAJOR comments:

(1) Line 7-8, paragraph 1, page 1

At the end of the first paragraph, the manuscript argues that the lack "of clear quality assu rance systems" is one of the two main factors leading to the "training gap unaddressed".

However, the rest of the manuscript fails to elaborate this key point. The end of the second paragraph mentions accreditation, which is part of the "clear quality assurance system". Except for this, the quality assurance system is rarely touched on, even in the "how to fix $t$ he problem" section. It is better if more attention can be paid to how to establish a wellfunctioning quality assurance mechanism nationally such as accreditation, individual certi fication, and training of trainers.

\section{RESPONSE:}

We fully agree with the reviewer that it is necessary to address quality assurance system in the "how to fix the problem" section. We have added the following statements to Line 88-101 of this revised manuscript, which now read:

Assessment systems are needed which emphasise teaching and not only surgical output. ${ }^{19}$ And as in other countries, accreditation of teaching hospitals should be based on assessment against national criteria and annual audits on performance. National standards should also be established for training and certification of trainers. As the largest national association of 
medical professionals in China, the Chinese Medical Association (CMA) is well positioned to help the government gather front-line data and make informed decisions. Adequate governmental financial support for resident training programs is also needed. The twin burdens of paperwork and research on young trainees must also be rationalised. Doctors and hospitals need to be transparent with patients about their teaching responsibilities, with clear protections in place for patients, including adequate supervision of trainees. Further research is needed documenting how these approaches can best be implemented, and tracking their impact on the problem."

(2) All the references had better be reviewed very carefully. I found at least several references problematic.

Reference 12 -

This very short "Letter to the Editor" is about China's general practitioners rather than ge neral surgeons. I am confused by this reference which has nothing to do with the argumen $t$ "the majority of general surgeries in large Chinese tertiary hospitals were performed by a small pool of senior doctors" (Line 3-4, paragraph 3, page 1).

Reference 23 -

This case by itself is controversial. More importantly, the website provided is the Chinese version of Wikipedia which probably everybody can edit. This is kind of a story telling whi ch may not be proper to be cited in a top academic journal article.

Some other reference problems will be mentioned later in the MINOR comments. Overall, I suggest the authors review all the references and evidence again with caution.

\section{RESPONSE:}

Reference 12 has been replaced by the following paper:

Zheng J, Zhang B, Yin $Y$, et al. Comparison of Plastic Surgery Residency Training in United States and China. Ann Plast Surg 2015; 75(6): 672-8.

This paper has pointed out that only surgeons with top technical titles could be considered as fully trained and eligible for practising independently. Surgeons without top technical titles can only assist in surgery, write prescriptions, and administer treatments and medications as a part of a treatment team, which includes 4 to 6 surgeons with different technique titles carrying out similar jobs but are not allow to provide surgical.

The case study on Xiong Zhuowei (Line 83-85), which served as the evidence for patients' unwillingness to involve young trainee doctors in the surgical practice, has been removed together with Reference 23. We have retained a reference on violence against surgeons from the Lancet.

(3) Some information is from 2013, around three years ago. The manuscript needs an upda te, as for the past three years China's residency has experienced many huge changes. I a $\mathrm{m}$ giving three cases from the manuscript here.

First, Line 4-5, paragraph 4, page 2

"the Chinese government must invest in supporting the costs of training, rather than simpl y passing these on to overwhelmed hospitals"

In fact, since 2014 the central government of China has decided to provide RMB $\mathbf{3 0}$ thousa nd Yuan per resident per year. Also, the local governments are encouraged to provide addi tional funding for residency training. At least in 2015 the funding from the central governm ent was supposed to have reached each of the 559 national training bases (which are all bi g tertiary hospitals). 
We agree with the reviewer that China's government has started the investment on the implementation of stardardised residency training, although the investment of the Chinese government in this crucial area still has room to grow. 30,000 RMB per resident is about US $\$ 5000$ (2/3 of which is used for living expense of the trainees rather than training costs, www.nhfpc.gov.cn/qjijs/s3594/201409/9175375bdc7a46b78bdcc0e35a480728.shtml), whereas in the United States, the government payment per resident per year is in excess of US $\$ 120,000$. Due to limitation in the total number of words, we have decided to focus more directly on quality assurance instead. Lines 88-93 now read:

"How to fix the problem? In the first place, the Chinese government clearly must mandate reasonable training models and minimum numbers of cases that reflect international standards. Assessment systems are needed which emphasise teaching and not only surgical output. ${ }^{19}$ And as in other countries, accreditation of teaching hospitals should be based on assessment against national criteria and annual audits on performance. National standards should also be established for training and certification of trainers. As the largest national association of medical professionals in China, the Chinese Medical Association (CMA) is well positioned to help the government gather front-line data and make informed decisions. Adequate governmental financial support for resident training programs is also needed."

\section{Second, Line 8-9, paragraph 2, page 1}

"the Chinese Ophthalmological Society has recently proposed a target of 15 cases 8." The latest requirement was issued in August 2014 by the National Health and Family Plann ing Commission (NHFPC). Please check this official website of the NHFPC: http://www.nhfpc.gov.cn/qiivs/s3593/201408/946b17f463fa4e5dbcfb4f7c68834c41.shtml The second PDF file (almost 400 pages) includes the latest requirement for residency traini ng in ophthalmology. Theoretically, the "target of 15 cases" is a compulsory requirement $r$ ather than a proposal now. But I am not sure about what is happening in implementation. Also, reference 8 here is from a health forum, posted in 2013.

In addition, here "the Chinese Ophthalmological Society" is part of the Chinese Medical Do ctor Association (CMDA) or the Chinese Medical Association (CMA)? The role (or potential role) of the professional associations in China's residency deserves some discussions.

\section{RESPONSE:}

Many thanks. We have replaced Reference 8 with the following:

Contents and standards of the standardised resident training programs. http://www.nhfpc.gov.cn/aijys/s3593/201408/946b17f463fa4e5dbcfb4f7c68834c41.shtml Last accessed: September 3, 2016

Line 30-32 now read:

"Differences in national requirements clearly tell a part of the story: the current minimum standard for cataract surgeries is 100 cases by the completion of residency training in HKSAR, 86 in both the United Sates ${ }^{5}$ and Singapore ${ }^{6}$ and 350 in the United Kingdom ${ }^{7}$, whereas the required number of cases for residents in training in China is only 15 according to regulations recently published by the Chinese National Health and Family Planning Commission. ${ }^{8}$

The Chinese Ophthalmological Society is part of CMA. We have now added some discussions on the potential roles of CMA/Chinese Ophthalmological Society in China's residency. 
Line 93-95 now read: "As the largest national association of medical professionals in China, the Chinese Medical Association (CMA) is well positioned to help the government gather front-line data and make informed decisions."

Third, Line 13, paragraph 1, page 1

"but the same consequences do not generally exist in China"

The residency training programmes have started to be evaluated since 2015. In fact, in 201 5 four residency training programmes were dismissed, and two training bases (hospitals) and 12 residency training programmes were warned. Whether this evaluation in China is $\mathrm{C}$ omparable to the accreditation in the US or Hong Kong needs further research. I suppose i f China strictly follows the accreditation standards of the US, most residency programmes may lose accreditation. But at least some mechanisms and efforts (as mentioned above) $h$ ave emerged, worth some elaboration.

\section{RESPONSE:}

We agree with the reviewer that this is a very positive trend, but that the situation is still accurately described by our wording: "the same consequences generally do not exist in China."

The role (or potential role) of the professional associations in China's residency deserves some discussions.

(1) Line 6, paragraph 1, page 1

Reference 2 -

the journal Zhonghua Yi Xue Za Zhi is quite a famous one in China. It has an official Englis h name - National Medical Journal of China

RESPONSE:

Many thanks. Correction has been made to the reference in this revision.

(2) Line 10-11, paragraph 2, page 1

"which does not appear to be the case in China3"

Reference 3 is a solid research, but it was conducted in 2012 before the start of this round of strong residency education reform. Compared to 2012, any progress or change for the $p$ ast two years? Given the authors are working at the front line of the residency, probably th ey can provide some first-

hand data in comparison with that in $\mathbf{2 0 1 2}$ so that some changes may be found.

\section{Response:}

The reviewer makes an important point. This is an inherent limitation of research, however: to carry out a detailed survey of resident performance and attitudes is costly and time-consuming, and we are unaware of any recent updates to the data provided by Reference \#3. Anecdotally, the authors have not seen major changes at the facilities with which they are most familiar, which are representative of the large institutions included in reference 3. At the end of the day, we are limited to an extent to draw inferences from the published literature.

(3) Line 3-5, paragraph 1, page 3

"Chinese physicians themselves need to find a way to heal the badlywounded bond between doctor and patient".

This statement is a little vague. Chinese physicians are also the victims of the poor doctorpatient relationship, the flawed health system lacking appropriate design, the twisted ince 
ntive, the over-

commercialisation and specialisation. How could they find a way to solve this? As mentio ned above, following the international experiences, strengthen the role of professional ass ociations which can represent doctors and assure quality and trust? Alternatively, improv e the humanistic education (communication skills, ethical standards, empathy with patient s, etc.)?

\section{RESPONSE:}

While the authors agree that both patients and doctors hold important responsibility for the current conflict in medical care, we do feel it is appropriate to expect doctors to play the leading role in addressing this problem. Improved standards of professionalism, as advocated in this piece, are a key step in this direction.

Reviewer \#4: I appreciated the opportunity to read this Viewpoint. I think that this is an imp ortant and urgent topic and overall, was quite clearly articulated for a broad audience. In y our second paragraph, you have characterized the "biggest challenge facing surgical train ees at all levels... is the lack of hands-

on learning opportunities". I am from a large, but comparatively sparsely populated countr y (Canada). When I was working in China and participating in rounds, one of the first thing $s$ I recall was that there was no shortage of patients; indeed there was a very large lineup. However, the process of conducting rounds was drastically different from my experience $h$ ere and in other countries. The senior in charge did all the hands on work, in silence. Ther e was no discussion, and the trainees all crowded around the room in silence. I came to un derstand from my Chinese colleagues that this was a cultural issue; that the prestige of th e senior's position could not be

maintained if he shared his expertise with a crowd of people eager to 'take' his knowledge, so he protected it.

In your paper, you address some very real contributions to the concentration amongst sen ior surgical practitioners, and the consequences of not addressing this issue. My suggesti on is that it is not only about the economic driver (pay per case) or the low value placed on teaching and education (true elsewhere sadly), but it is also a deeply entrenched cultural $i$ ssue. It is also a question of values. Can we improve the system without exploring the valu es that underpin them? In your suggested solutions, you argue for reasonable training mo dels. I have worked with medical professionals around the world, and it isn't simply a case of fixing the curriculum. New ideas popped into an existing culture or infrastructure are sa dly doomed to fail. In my experience, the 'fix' is not so simple, and until and unless we rec ognize that it is a question of values, and a question of changing the culturesomething that takes time that most do not want to invest - the 'fixes' are doomed to fail. For me, it is not only about patients trusting their younger surgeons; it is about a cultu re that is trusting the system to work well for them. Currently, it appears to be more selfserving than serving the needs of the people that a move toward a social healthcare syste $\mathrm{m}$ is designed for. I think that contextualizing your considerations of what it will take to ' $f i$ $x^{\prime}$ the situation by addressing these complex issues in more depth, will strengthen your th oughts about this.

\section{RESPONSE:}

One of the authors (Congdon) is a US-trained physician who has been studying Chinese and living there off and on for over 35 years. He and the other authors agree that cultural issues are of vital importance here, and exceptionally difficult to change. Books can (and have) been written about the impact of China's culture on training and education, but in view of our 1500 word limit, 
we have tried to summarize many decades of thoughts on this question as follows in the final paragraph (Line 103-116), which is fully focused on cultural issues:

"Other issues are more challenging to manage, none more so than China's culture, among the world's oldest and greatest. China's Confucian veneration of learning has done much to propel the country to its current place as a world leader, but it is fair to say that deep Chinese respect for teachers might be an even more potent force if matched with commensurate regard for students. Further, compared to the situation in America and Europe, a profound lack of trust exists between doctors and patients in China, which contributes for example to well-publicised cases of assault against physicians. ${ }^{20}$ This is to some extent a product of the rapid commercialization of medicine in China, as with so many other facets of society. For patients to place their sight or health in the hands of a younger, less-experienced surgeon is ultimately an act of faith, predicated on mutual respect and concern for well-being. China desperately needs to train a new generation of hands to take up the scalpel now and in the future. Bureaucratic reforms are urgently needed as part of the solution, but will go only so far to address the problem. China's senior physicians themselves need to find a way to bring young colleagues forward more efficiently, and to heal the badly-wounded bond between doctor and patient." 